\title{
Academic and Applied Policy Studies
}

\author{
A Comparison
}

DON E. KASH

STEVE BALLARD

University of Oklahoma

Policy studies continue to be prominent both in the making of American public policy and as a research focus in several academic disciplines. They have experienced particular growth in the discipline of political science (Hansen, 1983). Yet little agreement exists about how policy studies should be conducted or what their role in the policymaking process should be. This article investigates the differences between academic and applied policy research and, based on these differences, makes several observations on the future of policy research. Particular emphasis is given to issues of the relevance and utilization of policy research.

Academic and applied policy research can be distinguished by their different motivations. Applied studies attempt to address the information needs of policymakers with the goal of improving the policymaking process in the short term; academic studies attempt to improve basic understanding of how policy is made and implemented with the goal of improving policymaking over the long term.

The descriptions, observations, and findings presented in this article are derived from three sources. First, our own experiences in performing applied policy studies for government agencies were used to structure the study and to identify research questions. These experiences include both producing studies for specific clients and being involved in the process of applied research-serving on advisory committees, chairing review panels, testifying, and so on. Second, we have conducted informal interviews with several academic colleagues and knowledge users involved in policy research. Third, we have attempted to add to our knowledge about policy studies by reviewing and evaluating two 
contrasting approaches: The articles published in Policy Studies Review and Policy Sciences from 1982 through 1984 (academic studies) were compared with selected recent studies published by the National Research Council (NRC) and the Office of Technology Assessment (OTA) (applied studies).

The NRC is the operating arm of the National Academies of Science and Engineering and the Institute of Medicine. These institutions operate under a 1862 congressional charter, which specified that the academies provide advice to the federal government on scientific and technical issues. The two academies are honorific organizations, the members of which are the most distinguished American scientists and engineers. The Office of Technology Assessment is a research organization of the U.S. Congress established in 1972 to advise Congress on scientific and technical issues. The overwhelming portion of the studies carried out by the NRC are undertaken at the request of the executive agencies, and those carried out by the OTA are generally at the request of committees of Congress.

\section{CHARACTERISTICS OF THE RESEARCH}

\section{LINKAGES BETWEEN ACADEMIC AND APPLIED STUDIES}

A fundamental question of our research was the extent to which linkages exist between academic and applied research. Since OTA and the NRC frequently rely on university-based advisers or participants, and since many academic policy researchers pursue applied research objectives, our expectation was that many similarities would exist between the two forms of research.

However, our review of the journals and our interviews with colleagues suggest that the two types of policy studies are largely independent. Similarities exist at the most general level only; that is, both academic and applied studies share a focus on actions taken in and through government to resolve public issues or problems. The practitioners of the two types of studies are members of different communities who make little use of each other's work. No references were found to an NRC or OTA study in the three volumes of the Policy Studies Review and only one in Policy Sciences. Similarly, we found no references in the 
NRC and OTC studies to articles in the two journals. This lack of an obvious, direct linkage between the two communities is supported by a more in-depth assessment of the approaches, objectives, intellectual values, and audiences reflected in the reports and journals we reviewed. These factors are discussed below.

\section{OBJECTIVES, AUDIENCE, AND FOCI}

Academic and applied studies both aspire to relevance. The goal of relevance is, of course, a given for applied work. To a greater extent than we anticipated, relevance is also an articulated goal of academic studies. In the case of Policy Sciences, the pursuit of relevance is reflected in its subtitle: "An International Journal Devoted to the Improvement of Policy Making." In the case of the Policy Studies Review the editors state that the journal "enables one to be well informed concerning policy studies and their relation to improved productivity in the public and private sectors." The view that work published in Policy Studies Review is policy relevant is a repeated theme of the editors of many of the special symposia published in the journal. For example, the editors of the symposium on rural policy state, "These articles offer observations that can be directed toward the development of rural policy" (Browne and Hadwiger, 1982: 10).

Beyond a shared aspiration for relevance, however, academic and applied studies have little in common. In fact, the most striking finding of our assessment is how much and how broadly they differ. These differences begin with who initiates the studies and why they are undertaken. Studies published in the journals are typically initiated by the authors, who are predominantly faculty members at universities or professional policy analysts working for policy research organizations. The primary audience for these studies consists of the research peers of the authors. In contrast, the studies published by the NRC and the OTA are initiated by officials or institutions of the federal government. The applied studies are organizational products and their immediate audience is the requesting party.

In our opinion, this different starting point is fundamental to the differences found between the two approaches. For applied studies, relevance requires the capacity to meet the information needs of specific clients. This relationship provides an abundance of incentives for the applied researchers to produce usable results. In contrast, while 
relevance is clearly desirable on the part of many researchers, the nature of their work provides few incentives to work directly with knowledge users. Thus relevance in academic studies frequently is defined as addressing a policy-relevant topic.

The two types of studies have distinctively different foci. Academic studies generally have one or some combination of three foci: improved methodology, increased understanding of the policymaking process, or increased understanding of policy outcomes. Applied studies are virtually never oriented toward methodology; rather, they investigate the substance of a problem area and the options for dealing with the problem.

Academic studies are fairly evenly distributed among methodology, process, and outputs. Studies that focus on methodology range from investigations of specific tools, to comparisons of approaches, to investigations of the people, organizational arrangements, and research strategies used in, or appropriate for, policy research organizations.

Process studies generally fall into one of two groups. One group includes those studies concerned with a specific phase of what academics widely accept as the "policy system" model. This model appears in many variations, but it normally includes at least five phases: (1) input, (2) formulation, (3) conversion, (4) output, and (5) feedback. Recently, a variation of the conversion phase, implementation, has received major attention (Hansen, 1983). The second group of process studies focuses on the various phases of the policy system within generic areas such as regulatory policy, rural policy, and innovation policy. Specifically, these studies investigate political behavior within each of the phases and how the phases interact. The primary concern of both groups of process studies is with who participates, why, and how.

The third focus of the academic studies is on the specific outputs of the policymaking process-laws, regulations, programs, services, and so on. Within this third group, policy is generally viewed as the result of the policymaking process. Studies that investigate specific policies normally seek to provide understanding of how well policies work. These academic studies characteristically explain success or failure in terms of the policy's sensitivity to institutional, social, political, or economic conditions. An illustration of the criteria used in academic studies is reflected in the following quote:

The history of the U.S. industrial policy reads much the same as the history of U.S. innovation policy: government actions such as subsidies, tax benefits, tariffs, and 
economic regulations typically have been enacted in response to a clientele group, industry, or short-term situations with little or no consideration of the impact of or interaction with other policies affecting industry.... All other things being equal, the more strategically oriented the innovation policy, the better the economic performance [Roessner 1984: 430-431].

The general tenor of academic analysis is that policies succeed or fail as a result of the particular political conditions that created the policy or because of the social-institutional circumstances under which the policy is implemented. Thus the variables used are those common to the social sciences, but are not those normally used by policymakers. Typically, little attention is paid in academic studies to the question of whether or not the variables are, in fact, controllable by policymakers.

Applied studies generally have two foci. First, they focus on the substantive conditions that have created issues or problems. Thus, for example, accurate descriptions of physical conditions, trends, and affected people or areas are very important to applied studies. Second, while applied studies are similar to academic studies in being concerned with outputs or results, the specific emphasis is quite different. In applied studies, few attempts are made to explain policy outputs using the variables commonly found in academic studies; rather, the emphasis is usually on how policies are used as instruments by the government to influence, manipulate, or control substantive activities or circumstances. Applied studies, then, start by seeking to understand what substantive conditions caused the issue or problem; this is followed by efforts to understand how policies influenced those substantive conditions and what options exist to redress or resolve the problem.

\section{EMPHASIS ON USE}

One of the most striking distinctions between academic and applied studies concerns the attention paid to the application of their findings to problem solving. Academic studies attempt to be relevant by increasing the understanding of specific policies, the policy process, or the methodology of policy research. However, because the authors' audience is composed of their own peers, virtually no attention is paid to specific applications of their findings. For example, in spite of the explicit goals of Policy Science to improve policymaking, we could find only one article in three years (Brunner, 1984) that addressed application of knowledge as a central theme. Indeed, it is extremely rare to find an 
article in either journal that mentions application or utilization (see Richardson, 1983 and Seidel, 1983 for exceptions). We found no articles during this time period that empirically evaluated the utilization of an academic policy study.

Our assessment clearly supports past literature regarding the difficulty that academic studies have in achieving relevance and use (Glaser et al., 1983; Ballard and James, 1983; Lindblom and Cohen, 1979; National Research Council, 1978). With few exceptions, academic studies are not reported in the mass media, they are not referenced in congressional hearings, and their authors are not requested to appear before congressional committees or to participate as consultants or advisers in the policymaking process.

Applied studies offer a striking contrast. Almost without exception they have specific short-term applications as their goal. They are requested because congressional committees or executive agencies are currently faced with or anticipate being faced with problems. NRC and OTA studies are regularly referred to in congressional hearings and referenced in congressional documents, and their authors frequently testify before congressional committees. NRC and OTA studies are regularly reported in the media and referred to by a range of the actors and interests who participate in the policy process.

Like academic studies, applied studies seek to reduce uncertainty. They do not, however, assume that the primary way to do this is by establishing cause and effect relationships or by formulating general rules or conceptualizations. Rather, applied studies assume that the cause of problems and issues is rooted in substance; therefore, applied studies are much more concerned with developing accurate descriptive information about substance and with identifying and comparing alternative ways government can influence substantive activities. Thus the "successful" applied study is frequently one that informs policymakers about the nature of problems and issues and increases knowledge about the trade-offs associated with different courses of action.

The character of applied studies can be illustrated by two done by the NRC and one by OTA (National Research Council, 1981; National Research Council, 1985; Office of Technology Assessment, 1985). Many NRC studies go no further than trying to define substantive uncertainties. Yet in accomplishing just that much, they can become important factors in the policy process. An example of this is an NRC report entitled "Atmospheric-Biosphere Interaction: Toward a Better Understanding of the Consequences of Fossil Fuel Combustion" (National 
Research Council, 1981). This report concluded that in the most seriously impacted fresh water ecosystems it would be desirable to have a reduction of $50 \%$ in the deposited hydrogen ions. The report was important because it indicated that acid rain was a problem that could be resolved by reducing those substances that the evidence indicated were the cause of the problem. Thus the report had substantial influence on the policy debate by proposing an acceptable pollution standard.

A different kind of NRC report is illustrated by a study entitled "Dredging the Coastal Ports: An Assessment of the Issues" (National Research Council, 1985). Although the report focused on a much narrower issue than acid rain, it took a much broader look. The study was initiated because of a perception that the United States was suffering economic losses as a result of its inability to load and unload large deep draught ships. This inability resulted from channels into and out of U.S. ports that were too shallow. The information need was to identify the costs and benefits associated with deepening existing ports. The study concluded that more benefits than costs were associated with dredging. It then investigated the barriers to dredging and presented some 32 findings, a number of which were in effect recommendations for modifications in existing port policy. It is important to note, however, that the vast majority of the report is concerned with trying to understand and reduce the uncertainty associated with the substance of the issues. The policy recommendations flowed from substantive findings.

The OTA illustration is a study entitled "Oil and Gas Technology for the Arctic and Deep Water” (Office of Technology Assessment, 1985). This study starts by assessing the nation's oil and gas situation, followed by an attempt to identify the potential resources available in arctic and deep water. It then investigates what kinds of technologies are necessary to produce oil and gas in these hostile areas in an environmentally acceptable manner. Following the investigation of these substantive questions, the study defines a variety of options that Congress might consider in seeking to accelerate the discovery and production of oil and gas in arctic and deep water. The OTA study is characterized, as were the NRC studies, by starting with a focus on substantive information and trying to define the character of uncertainty with regard to that information.

In summary, the approach to utilization of academic and applied policy studies is dramatically different. Applied studies are selfconsciously concerned with application of their results in the short term 
and their success is measured by the extent to which they inform policymakers on substance. Applied studies appear to be successful regardless of the extent to which they present findings in a cause-andeffect mode; indeed, credible characterizations of substantive conditions are sufficient for enhancing the policymaking process. Academic studies evidence typically shows little concern with short-term application or the reactions of the policymaking community to their findings. Success in academic studies appears to be measured by the reactions of the researchers' peers.

\section{SPECIFICITY VERSUS GENERALITY}

Academic studies differ from applied studies in the extent to which they attempt to understand policy at highly general levels. General findings are seldom directly useful to policymakers. For example, special issues of the two journals addressed such topics as "regulatory policy," "rural policy," and "risk policy." The editor of the symposium on risk states that "when institutional and procedural aspects are better understood, it may be possible to develop a more coherent general theory of risk"(Hadden 1982: 651). Since policymaking is not organized around these broad generic areas, they are of little immediate utility to policymaking. Policymakers are much more likely to be interested in studies that inform them about how to regulate cotton dust in an efficient way or how to control the pollution threat from septic tanks.

The following quote from an article investigating government housing policy suggests the generality of academic conclusions:

\footnotetext{
What policies are needed to rectify this situation? Some might say that no policy changes are necessary because there is a package of existing policies which substantially rectifies problems caused by reliance on a biased market. Indeed, there are policies that provide mortgage insurance in communities which lenders perceive as high risk. Statutes also exist that forbid steering and other segregationist practices. The problem is that these statutes are poorly enforced. Likewise, the programs to insure lending in minority communities are minuscule in comparison to side of market forces working in the opposite direction. Simply put, more direct interventions are necessary [Thompson, 1983: 70].
}

While this recommendation may be based on accurate information, it does not identify any direct policy intervention nor does it address the key questions required by policymakers, such as the trade-offs associated with different courses of action or the political feasibility of specific direct interventions. 
Applied policy studies generally provide more detailed and specific findings and sometimes they identify highly specific ways of addressing the problems. For example, a recent NRC report on earthquake engineering facilities had the following recommendation:

The federal government should immediately initiate a conceptual engineering design study of a national earthquake engineering experimental/test facility capable of both dynamically and statically testing full or nearly full-scale multistory buildings to destruction in a simulated earthquake environment [National Research Council, 1984].

Because of the values associated with scientific research, academic studies tend to identify general problems and general solutions. Applied policy studies tend to identify specific substantive problems and make specific substantive findings or recommendations. Thus the priorities of applied policy analysts are to address the information needs of policymakers, frequently including the details of current laws and regulations. They are less likely to be concerned with methodology than is the academic researcher.

\section{THE RESEARCHERS}

While applied research studies are usually the product of interdisciplinary research teams, academic studies are typically the product one or two authors from the same or a very closely related discipline. Of the 202 journal articles we reviewed, $64 \%$ were single authored and $30 \%$ had two authors. The remaining $6 \%$ had three authors; none were produced by larger research teams. Most of the authors of the academic studies were social scientists, both in terms of training and chosen career. For example, in Policy Studies Review only 3\% of the 183 authors were not social scientists; these authors were primarily from business-related disciplines. Fifty-eight percent were political scientists, public administrators, or were associated with schools of public policy and public affairs. Fewer than $10 \%$ of the authors held nonacademic positions at the time of publication, and most of these held doctoral degrees in a social science.

In contrast, the studies published by the NRC and the OTA are the products of research teams that are multidisciplinary or interdisciplinary in character. The vast majority of those involved in preparing OTA and NRC studies are people with natural science or engineering backgrounds with substantive expertise in the arena under study. 
National Research Council studies are normally carried out by committees or panels, the members of which have diverse substantive expertise. The panels tend to be mixtures of physicists, chemists, biologists, engineers, and social scientists. Panel members are normally established experts in the area of substance being studied. A central goal of the National Research Council in selecting committee members is to assure that they can provide state of the art knowledge of the substantive arena. Members of National Research Council committees and panels are, with few exceptions, drawn from nonfederal organizations with the primary sources being universities and business organizations. These committees and panels are supported by full-time NRC staff members whose activities may range from coordinating the members of the committee to preparing drafts of the report based upon the committees' work.

The NRC seeks to assure that its studies have both credibility and legitimacy by careful selection of the members on the study committees. By selecting established experts in the substantive area, the National Research Council panels start with scientific-technical credibility within the expert community concerned with any substantive policy area. The second type of credibility sought by the NRC in selecting its study committees or panels is social-political-economic disinterestedness or, alternatively, balance. Where possible, the NRC selects panels of experts who have no economic or institutional vested interest in one or another policy outcome. In practice, it is frequently difficult for the NRC to find experts without some kind of economic or institutional vested interest. When that is the case, the NRC addresses the vested interest problem by assuring that the study committee reflects the full spectrum of economic and institutional vested interests. As an example, studies dealing with offshore oil development are likely to have representatives of state environmental agencies, environmental interest groups, the oil industry, and university professors.

OTA studies are carried out by the full-time staff of that organization. These studies normally involve a number of OTA staffers who themselves represent a diversity of disciplinary backgrounds and expertise. In addition, OTA contracts with expert consultants or researchers for the collection and analysis of substantive information. In addition, OTA studies are normally advised and reviewed by panels composed of outsiders. These advisory panels have many of the same characteristics of the study committees of the NRC. First, the OTA seeks to select advisory panel members who represent a diversity of 
disciplines and have state of the art expertise in the substantive area. The advisory panels tend to be predominantly made up of natural scientists and engineers but they normally also include social scientists and frequently attorneys. In addition, OTA advisory panels are selfconsciously selected to represent the full range of parties-at-interest, or stakeholders, concerned with the policy under study. These advisory panels normally meet three times. The first meeting is to advise OTA on how to frame the study and where to go for appropriate information and insights. The second panel meeting normally occurs when the OTA staff has major components of the study prepared in a first draft form. The third meeting reviews the completed draft of the study.

Meetings of both NRC study committees and OTA advisory panels are normally attended by officially designated liaison representatives from those federal executive agencies or congressional committees to which the study has relevance. Although these liaison people normally play a passive role, they provide the studies with current data and information and they sensitize the studies to current issues. In combination, the liaison people and the OTA and NRC staffers provide the applied studies with information on political nuances.

Specifically, applied studies are sensitive to the attitudes and positions of key individual policymakers, both members of congress and executive officials. The importance of key individuals in some areas of policy would be missed completely if all one did was to read the written reports or articles. In fact, in some areas of policy individual policymakers develop personal objectives and agendas that are not explained by interest group demands. These deep personal commitments assure long-term, sustained efforts by the individuals to bring about policy changes. Within both executive agencies and Congress, these commitments become known and are critical ingredients in the calculus of policymaking.

\section{CHARACTERISTICS OF THE STUDY PROCESS}

Another striking difference between academic and applied policy research concerns how the research is communicated to potential audiences. Academic researchers communicate with their audience through the publication of their findings or through the presentation of 
those findings at professional meetings. The audience for academic studies, then, only becomes aware of the specifics of the study when it is completed and the results are published.

Applied policy studies involve a process of communication with the interested audience that begins when the study is initiated. The linkage between the applied policy study process and the audience usually begins, in the case of both OTA and the NRC, with negotiations between these organizations and the requesting agency or committee. These negotiations are generally concerned with defining the scope of the study and its particular emphasis. It is normal for the staffers at both OTA and the NRC to maintain a dialogue with the interested agencies or committees throughout the course of the study.

As previously noted, another important communications network is established when the NRC selects the members of the study panel or the OTA selects the members of the review committee. Since in both instances the members of these committees are either substantive experts or interested parties, they serve as continuing communication links between the study and the interested policy community throughout its duration. The committee members offer the NRC and OTA assurance that all of the information perceived as being relevant by the interested policy community is made available to them. Further, the members of the study panels or advisory committees serve to assure various interested parties that the study is being carried out in a balanced manner and that due consideration is being given to both all of the information and all of their concerns.

It is the goal of NRC studies that their analyses and findings will be formulated such that all of the members of the study committee can agree; that is, the goal is consensus. In the case of OTA the review panels are advisory and the pursuit of consensus is not a formal goal. In fact, however, the OTA study process strives to achieve consensus. Consensus in both instances does not necessarily mean that each panel or committee member agrees in every detail. Rather, it means that none of them disagree so strongly that they are prepared to go public in their disagreement with the study findings.

The nature of both OTA and NRC study processes, then, means that the studies become a part of the policymaking process while they are being carried out. Although applied studies do not specifically address the policymaking process in their written reports, the way in which they are carried out sensitizes them to that process. Thus the studies tend to serve not only as mechanisms for informing policymakers, but they 
frequently also serve the process of building consensus or finding compromise within the policy community. It is, for example, useful to federal agency or congressional decision making to have representatives of opposing interests supporting common findings or common recommendations at the time decisions are made. These communication patterns also tend to reduce to a large extent problems associated with timing - that is, whether or not policy analysis is completed in time to inform policymaking. While this is seldom an issue in applied studies, it is a major barrier to the application of academic studies carried out without these linkages (Ballard and James, 1983).

As a consequence of the way in which NRC and OTA studies are carried out, by the time the study is formally published it may very well be anticlimactic. Members of the policy community concerned with a particular substantive area will almost certainly already have been aware of the findings and, not infrequently, those findings will already be a part of the discussion and the debate going on within the policy community.

\section{CONCLUDING OBSERVATIONS}

Our review of the two bodies of research suggest the following perspectives about how policy research is conducted in two settings:

(1) Few identifiable linkages exist between academic and applied studies.

(2) Academic studies are investigator-initiated, while applied studies are userinitiated.

(3) Academic studies focus on methodology, process, and outputs. Applied studies focus on the substantive activities for which policy is made, and they approach policy as the instrument that government uses to manipulate substance.

(4) Academic studies have as their primary goal increased understanding of general policy areas, the policy process, or the methodology of policy research. Academic studies are focused on an audience of peers.

(5) Academic studies pay very little attention to the actual application of their findings and little effort is made to assure policymakers are aware of their work.

(6) Applied studies emphasize improved understanding of substance; thus a primary focus is on identifying the utility of alternative approaches to government to manipulating that substance.

(7) Academic studies address general or generic policy areas such as regulatory or rural policy. Applied studies address specific areas, such as cotton dust or port dredging. 
(8) Academic studies are normally carried out by one or two researchers, usually social scientists. Applied studies are normally carried out by teams of natural scientists, engineers, and social scientists.

(9) Academic studies communicate their results through publication, while applied studies communicate through both the study process and final published reports.

(10) Academic studies seldom deal with substance or with the role of individuals. Applied studies seldom explicitly evaluate process or individuals, but because of the way they are carried out, they are sensitive to both process and individuals.

Our assessment of academic and applied policy studies leads to three conclusions. First, relevance and usefulness have very different meanings depending upon who is doing the research. For academicians, relevance typically means studying broad, generic policy topics, rather than specific problems and issues. In addition, academicians typically endeavor to educate their peers rather than to inform policymakers. In applied policy studies, relevance often means providing descriptive information that can reduce the substantive uncertainties of policymaking. Applied studies are much more concerned with the information needs of users, the timing of decision making, and specific options that are controllable by policymakers.

Second, if the studies reviewed here are typical of the larger set of academic policy studies, it should not be expected that most academic policy studies will be used for either short-term or long-term policymaking. This might be expected with regard to short-term usefulness, since the primary academic concern is with developing more general and broadly applicable understanding of policy and policymaking. Unfortunately, it also appears that academic studies are unlikely to have much application over the long term because they do not adequately address the substantive content of public policies or because they try to develop generalizations about substantive topics that are very diverse and continually changing.

Third, the kinds of applied policy studies reviewed in this article have clear advantages over academic studies in terms of utilization. In short, they begin by developing interaction between the knowledge producer and the knowledge user. However, they also self-consciously address the roles and relationships among three factors: process, substance, and key individuals. If application is to become an important objective of academic studies, the OTA and NRC examples would provide good models for addressing these key requirements of useful policy research. 


\section{REFERENCES}

BALLARD, S. C., and T. E. JAMES, Jr. (1983) "Participatory research and utilization in the technology assessment process: issues and recommendations." Knowledge 4: 409-427.

BROWNE, W. P. and D. F. HADWIGER [eds.] (1982) "Symposium on rural policy." Policy Studies Rev. 2: 9-11.

BRUNNER, R. D. (1984) “Integrating knowledge and action." Policy Sciences 17: 3-12.

GLASER, E. M., H. H. ABELSON, and K. N. GARISON (1983) Putting Knowledge to Use. San Francisco: Jossey-Bass.

HADDEN, S. G. [ed.] (1982) "Symposium on public policy toward risk." Policy Studies Rev. 1: 651-655.

HANSEN, S. B. (1983) "Public policy analysis: some recent developments and current problems," in M. Finifter (ed.) Political Science: The State of the Discipline. Washington, DC: American Political Science Association.

LINDBLOM, C. E., and D. K. COHEN (1979) Usable Knowledge: Social Science and Social Problem Solving. New Haven, CT: Yale Univ. Press.

National Research Council (1978) The Federal Investment in Knowledge of Social Problems. Washington, DC: National Academy Press.

National Research Council (1981) Atmosphere-Biosphere Interactions: Toward a Better Understanding of the Ecological Consequences of Fossil Fuel Combustion. Washington, DC: National Academy Press.

National Research Council(1984) Earthquake Engineering Facilities and Instrumentation. Washington, DC: National Academy Press.

National Research Council (1985) Dredging the Coastal Ports: An Assessment of the Issues. Washington, DC: National Academy Press.

Office of Technology Assessment (1985) Oil and Gas Technologies for Arctic and Deepwater. Washington, DC: Government Printing Office.

RICHARDSON, H. (1983) "The relevance of urban economic theory to urban policy analysis." Policy Studies Rev. 3: 45-51.

ROESSNER, J. D. [ed.] (1984) “Symposium on innovation policy." Policy Studies Rev. 3: 429-435.

SEIDEL, A. (1983) "Producing usable research: a selected review." Policy Studies Rev. 3: 52-57.

THOMPSON, L. (1983) “An assessment of urban reinvestment policy.” Policy Studies Rev. 3: 67-78. 